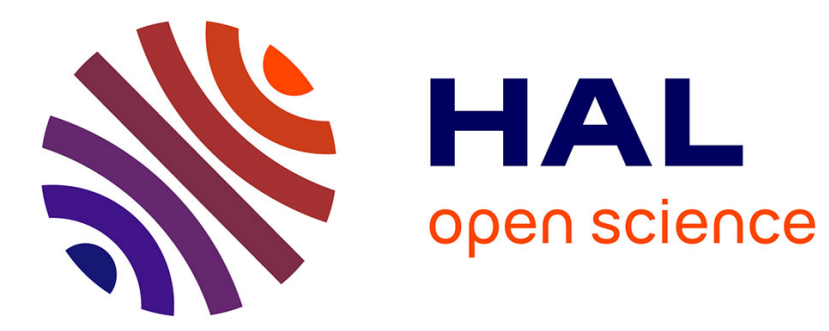

\title{
Postponement Revisited - A Typology for Displacement
}

Fredrik Tiedemann, Joakim Wikner

\section{To cite this version:}

Fredrik Tiedemann, Joakim Wikner. Postponement Revisited - A Typology for Displacement. IFIP International Conference on Advances in Production Management Systems (APMS), Sep 2019, Austin, TX, United States. pp.204-211, 10.1007/978-3-030-29996-5_24 . hal-02460514

\section{HAL Id: hal-02460514 https://hal.inria.fr/hal-02460514}

Submitted on 30 Jan 2020

HAL is a multi-disciplinary open access archive for the deposit and dissemination of scientific research documents, whether they are published or not. The documents may come from teaching and research institutions in France or abroad, or from public or private research centers.
L'archive ouverte pluridisciplinaire $\mathbf{H A L}$, est destinée au dépôt et à la diffusion de documents scientifiques de niveau recherche, publiés ou non, émanant des établissements d'enseignement et de recherche français ou étrangers, des laboratoires publics ou privés. 


\title{
Postponement revisited - A typology for displacement
}

\author{
Fredrik Tiedemann ${ }^{10000-0002-7190-9807]}$ and Joakim Wikner ${ }^{[0000-0003-2252-5337]}$ \\ ${ }^{1}$ Jönköping University, Jönköping, Sweden \\ \{fredrik.tiedemann, joakim.wikner\}.ju.se
}

\begin{abstract}
Since its introduction, postponement as a supply chain strategy has received a lot of attention in the operations management and the supply chain management literature. Nevertheless, there are still mixed answers about the meaning of postponement and as such, about its operational benefits. For instance, while some scholars argue that postponement results in a shorter delivery lead time, others claim the contrary. To reconcile these apparently conflicting findings, the purpose of this study is to establish a typology that highlights the three key properties of displacement, which is a collective term for preponement and postponement. By breaking down postponement into the three dimensions of form, place, and time, as well as introducing its antithesis preponement, a typology for displacement is presented and illustrated using a well-known postponement case.
\end{abstract}

Keywords: postponement, preponement, displacement, flow thinking, decoupling point

\section{$1 \quad$ Introduction}

Postponement, also known as delayed product differentiation [1-6], delayed differentiation [7], and late customization [4, 5], was already put in practice in the 1920s [810] but was initially introduced in the marketing literature by Alderson [11] as an approach to reducing or eliminating the risk and uncertainty costs associated with the differentiation of goods [e.g., 12-14, 15]. Since then, many success stories owing to postponement have been reported in the literature [e.g., 2, 16]. However, there are still mixed answers about the meaning of postponement. Starting with Alderson [11], several works [e.g., 2, 6, 16-19] define postponement as an approach to reducing or eliminating the risk and the uncertainty associated with the differentiation of goods, where the differentiation processes in a supply chain should be delayed as long as possible. The second group of works [e.g., 20,21] argues that the point of differentiation should be postponed as close as possible to the customer order entry (i.e., the customer order decoupling point [CODP]) but not necessarily at or downstream of the CODP. The third group [e.g., 9, 10, 12, 14, 15, 22-26] defines postponement as the delay of activities until customer orders are received, that is, at or downstream of the CODP. The mixed answers regarding the definition of postponement have obviously resulted in mixed answers about how postponement relates to operational performance and even why it 
is beneficial to pursue [27]. For instance, some authors argue that higher levels of postponement lead to longer delivery lead times [e.g., 12, 26], whereas others [e.g., 5, 28] claim the opposite. As such, what some researchers deem postponement might be considered preponement by others (preponement is a newer term, first mentioned by Blackburn et al. [3] and is here considered the antithesis of postponement). Thus, to reconcile these apparently conflicting findings, the purpose of this study is to establish a typology that highlights the three key properties of displacement.

Note that the movement of a transformation activity within a flow structure is here referred to as 'displacement' and is thus used as a collective term for postponement and preponement. In the next section, the idea behind postponement and its relation to the CODP is discussed. Thereafter, a typology for displacement is developed using the three generic dimensions of postponement, that is, form, place, and time [see, e.g., 7 , $11,29]$. The typology is then applied to one well-known postponement case. The paper ends with a discussion, conclusions, and further research.

\section{Defining form and place postponement in terms of the CODP}

For many kinds of products, the individual customer demand is unique, especially when taking into consideration the basic use, special features, colors, sizes, and places of purchase [11]. However, products belonging to the same family usually share common components and/or processes, meaning that in their initial stages of production, these products are in a generic form and place $[1,4,6]$. It is not until specialized components are inserted and/or special processes are performed that the items are progressively differentiated into specific end-products $[6,30]$, referred to as the point of differentiation [e.g., 1, 30,31]. Each step taken to differentiate a product based on speculation involves a certain marketing risk [11], that is, risk and uncertainty costs tied to the differentiation of the good $[23,32]$. The idea behind postponement is therefore to delay the points of differentiation, keeping products generic as long as possible. As such, despite the mixed answers about the definition of postponement, the general idea behind it is to reduce the risk of performing activities based on speculation (forecast), especially the activities related to variants and customization. Postponing such activities closer to or under a commitment from a customer order reduces the risk and uncertainty costs tied to the differentiation of goods $[23,32]$. The concept of displacement (i.e., postponement and preponement) is thus tightly related to the flow-thinking ontology [see 33], specifically the flow driver, that is, the CODP, which is the point that separates the forecast-driven part of the flow from the customer-order-driven part of the flow [34]. The position of the CODP then also coincides with the upstream part of the delivery lead time, which is the customer's requested delivery lead time [34]. It is thus logical that many definitions of postponement use the concept of a customer order [e.g., 9, 10, 12, 14, 15, 2026]. Pagh and Cooper [12] even state that the converse concept of postponement is speculation, that is, involving the activities carried out upstream of the CODP [34]. Forza et al. [27] use the CODP as a point of departure for creating their form postponement typology, which offers a coherent picture of form postponement and its effects on 
operational performance. Forza et al. [27] also mention that if the point of differentiation would be moved upstream, rather than downstream, the logical opposite of form postponement would be achieved, called form preponement in this paper.

Nevertheless, by defining form postponement or place postponement based on the customer order (i.e., the CODP), postponement can be achieved by simply extending the delivery lead time, that is, moving the CODP upstream in the flow. As such, several parts of the structure are added later and can therefore be considered postponed in relation to the CODP. This modification is illustrated in the time-phased bill of materials (BOM) in Fig. 1, where the left part of the figure is the state before the displacement and the right part is the displaced state (i.e., the postponed state). Before the postponement, the CODP is situated six time-units from the delivery of the product, that is, the delivery lead time consists of six time-units. In the postponed state, the delivery lead time is extended to ten time-units. As such, the transformation activities Q, U, V, and $\mathrm{W}$ are postponed in relation to customer requirements, where $\mathrm{U}, \mathrm{V}$, and $\mathrm{W}$ are even carried out after the receipt of a customer order. However, the word postpone means to put off to a later time, where pre means earlier than, prior to, or before. Postponement can thus be regarded as repositioning to a later point in time, with preponement being the opposite, repositioning to an earlier point in time. Both postponement and preponement are thus related to changes in an existing state, that is, repositioning an already existing position. For the example of Forza et al. [27], this means that the activities of form transformation are carried out closer to or upon request from a customer order (i.e., customer-order-driven). However, the form is still achieved at the same point within the BOM and the same time units before delivery. In other words, it still has the same flow structure, and the time required to perform the transformation activities remains the same. Arguably, the form has not been postponed. Even so, postponement and preponement are arguably tightly related to the CODP, but it might not be feasible to define postponement and preponement based on it, at least not for the concepts of form and place postponement.

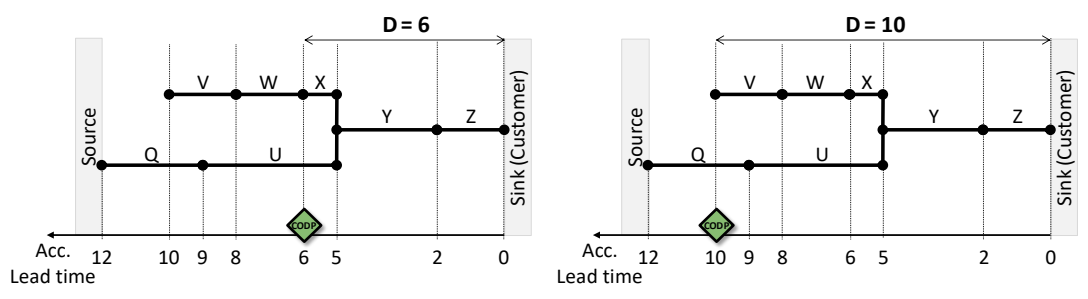

Fig. 1. Before versus after displacement, shifting the CODP upstream [based on 34].

\section{$3 \quad$ Creating a typology for displacement}

Both postponement and preponement have their base in the time dimension, meaning that a time-phased flow structure is a suitable starting point. This also basically means that both terms are based on displacement in relation to a fixed point of reference, which is the flow sink (customer) in this case (see Fig. 1). Regarding form transformation, it 
is essentially about transforming raw materials into a finished product in terms of physical aspects, such as size, color, shape, and function. As for place transformation, it involves relating identity not only to what (form) but also to where (place), which is the meaning of the term stock-keeping units (SKU), covering both form and place. Place is therefore related to having something at one location (central) or at several locations (local). Another important property of transformation is time (when). One conventional way of combining form and place with time is through a time-phased BOM; for an example, see Fig. 1. In contrast to a traditional BOM, a time-phased BOM is usually illustrated horizontally to clearly illuminate the time dimension of the activities performed. Each segment of the structures in Fig. 1 represents different transformations in terms of form and place. The time phasing means that each transformation step is offset by the corresponding time for each segment, that is, the lead time. Displacement of form and place transformation can be achieved by either creating new flow structures or changing the time required to perform the transformation activities. From a form perspective, this means that through postponement, the form is achieved later in the flow, by modularization, using standardized modules instead of building complete unique products from scratch, for instance. On the contrary, preponement could be used to create variants of a previously standard product.

Postponement in terms of place transformation usually refers to the differentiation in location performed at a later point in time, for instance, by keeping the products in a centralized warehouse instead of distributing the goods to local warehouses. This can be formulated as product proliferation in terms of the place property, which is done at a later point in time. Conversely, preponement means that product proliferation in terms of the place property is done at an earlier point in time to ensure local availability, for instance.

The third dimension is then time. Displacement of time seems that time is counted twice, but here, the term time refers to two different things. Displacement has traditionally referred to the change of the point in time when a transformation is carried out in relation to the requested delivery lead time [see, e.g., 27]. Displacement therefore conforms with the definition of the CODP [33]. To summarize, displacement and form, place, and time transformation can be combined in six different ways, as shown in Table 1. Basically, there are two types of changes in state. For form and place, the change is related to flow proliferation, with an 'absolute' displacement since it is made in time units. Time is then related to the flow driver and a relative displacement since it pertains to the delivery lead time. This also means that for form and place, the points of departure are the individual points of transformation in the flow, but for time, the point of departure is the CODP, which has its starting point in the delivery lead time.

Table 1. Combinations of displacement and form, place, and time properties.

\begin{tabular}{lll}
\hline \multicolumn{2}{c}{ Preponement } & Postponement \\
\hline \multirow{2}{*}{ Form } & A form transformation activity & A form transformation activity \\
& performed earlier in the flow structure & performed later in the flow structure \\
Place & A place transformation activity & A place transformation activity \\
& performed earlier in the flow structure & performed later in the flow structure \\
Time & CODP earlier in the flow structure & CODP later in the flow structure \\
\hline
\end{tabular}




\section{$4 \quad$ Applying the typology for displacement}

The relevant literature provides a vast array of examples of postponement as used in practice. One of the more famous and disseminated examples is the case of Benetton $[10,35,36]$. The new typology for displacement is here applied to this example to illustrate how the transformation process is changed in terms of the three dimensions.

Benetton's market strategy and product diversity are essentially based on colors [35]. In fact, the company is currently known as the United Colors of Benetton (UCB). In its initial manufacturing process, the company dyed its yarn in different colors before knitting it into finished garments [10]. According to the company, this process resulted in too many garments in different colors that the customers did not want, whereas the garments that the customers wanted were sold out $[10,36]$. UCB has since then changed the order of its dying and knitting process, using bleached yarn for knitting its garments and only dying them at a later stage when UCB either has received an order or has a better idea of which colors are selling [10]. Fig. 2 presents the UCB application of displacement. Note that the activities presented in the figure are based on the information provided by Yang and Burns [10]. However, the lead times and the time-phased BOMs are conceptually developed and merely used as illustrative examples when discussing the displacement in terms of the three dimensions. Note that each segment of the time-phased BOM represents the process to be performed and positioned as ending at the required point in time. In actual execution, different processes could be aggregated and performed simultaneously. For example, the two Qs at the very left of the 'before BOM' in Fig. 2 could be purchased at the same time despite having different requirement dates.

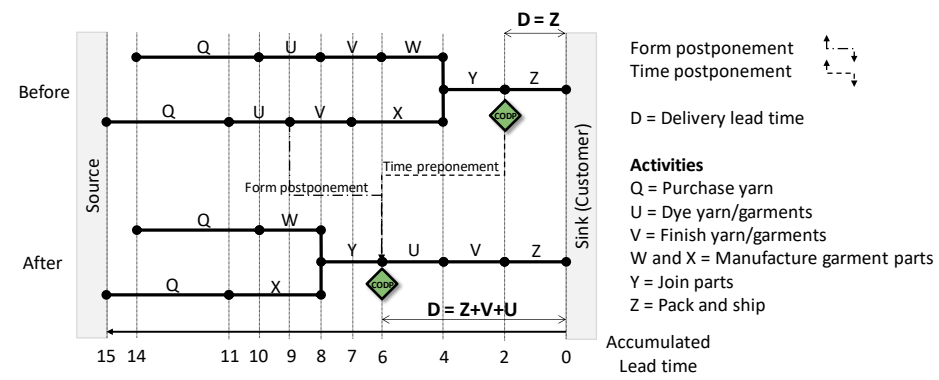

Fig. 2. Before versus after displacement carried out at UCB.

By changing the order of knitting and dying, the point at which the garments are dyed is postponed, that is, form postponement. Obviously, the garments are dyed later but probably done in the same factory as before and sold in the same retail stores as before. As such, there is no place postponement. However, it is not clear if the CODP has been shifted in time. According to Lee [36], in its before state, UCB used a make-to-stock strategy, manufacturing its finished products to stock, whereas in its after state, UCB now applies a build-to-order mode. As such, it could be argued that the delivery lead time has been extended (see Fig. 2), also including the dying of the garments. Thus, there is a time preponement. However, considering individual cases, in the new production process, some customers probably do not have to wait for garments that have 
been sold out. As such, it could be argued that the delivery reliability has increased, in line with the reported improvement in customer service [36].

\section{Discussion, conclusions, and further research}

The introduction states that there are mixed answers about the definition of postponement. In numerous scientific and managerial documents, postponement has been discussed as the delaying of activities, especially transformation activities associated with the differentiation of goods, and these activities should be postponed as long as possible $[2,6,16-19]$, closer to the CODP $[20,21]$ or even to or downstream of the CODP [9, $10,12,14,15,22-26]$. Moreover, this way of perceiving postponement is a bit onedimensional; thus, some researchers have discussed postponement by using one or more of the three dimensions, that is, form, place, and time [e.g., 8, 14, 25, 27, 29]. By using these three dimensions of postponement and including preponement, a more nuanced understanding of displacement is gained, creating the ability to compare different cases of postponement and their operational benefits. As shown in the illustrative postponement example of UCB, even though the company has achieved form postponement, there is no place displacement, and the delivery lead time has even been somewhat extended, resulting in time preponement. Furthermore, when creating the typology presented in this paper, the meanings of the words prepone and postpone are used as starting points. As such, the point of reference is changed from the CODP to the initial time at which a transformation activity is conducted in terms of form or place. This way, form postponement or form preponement cannot be achieved simply by repositioning the CODP upstream and downstream of the flow, respectively, for instance. However, the CODP is still used in terms of time postponement and time preponement. As such, the form and the place dimensions are related to whether a transformation activity is conducted based on speculation or on a commitment from a customer. In this way, the operational results of postponement and preponement can be taken into consideration, for instance, if an activity after the displacement can be performed based on a commitment from a customer, rather than on speculation. As such, the typology relates back to Alderson's [11] novel view of postponement as illuminating the risks and the uncertainties of carrying out certain activities based on speculation.

To conclude, the typology presented here uses the existing dimensions of postponement, that is, form, place, and time. However, form and place are not defined using the CODP, thereby excluding the view of merely repositioning the CODP as being the postponement of form and place. The typology also includes preponement, realizing that an activity can be preponed. As such, a typology for displacement (i.e., postponement and preponement) has been established. By utilizing flow thinking [33] and the CODP, a better understanding of the operational effects of a preponement or a postponement decision is also obtained. The established typology for displacement thus complements the literature on postponement and offers a more nuanced understanding of it. In turn, the typology can help managers make more nuanced displacement decisions by more clearly distinguishing between flow driver and flow differentiation in terms of form and place. 
However, further research could include specific studies on customization and variety in combination with preponement and postponement. Here, flow thinking, specifically the customer adaptation decoupling point and the system lead time [see, e.g., 33, 34], could assist in providing a better understanding of the operational implications of preponing or postponing a customization activity upstream or downstream of the flow, as well as whether a delivery-unique variant can be offered.

\section{Acknowledgement}

This research has been conducted under the KOPtimera project, funded by the Swedish Knowledge Foundation and Jönköping University.

\section{References}

1. Aviv, Y., Federgruen, A.: The benefits of design for postponement. In: Tayur, S., Ganeshan, R., Magazine, M. (eds.) Quantitative models for supply chain management, pp. 553-584. Springer US, Boston, MA (1999).

2. Aviv, Y., Federgruen, A.: Design for postponement: a comprehensive characterization of its benefits under unknown demand distributions. Operations Research 49(4), 578-598 (2001).

3. Blackburn, J.D., Guide Jr, V.D.R., Souza, G.C., Van Wassenhove, L.N.: Reverse supply chains for commercial returns. California Management Review 46(2), 6-22 (2004).

4. Garg, A., Lee, H.L.: Managing product variety: an operations perspective. In: Tayur, S., Ganeshan, R., Magazine, M. (eds.) Quantitative models for supply chain management, pp. 467-490. Springer Science+Business Media, New York, NY (1999).

5. Swaminathan, J.M., Lee, H.L.: Design for postponement. In: de Kok, SC., Graves, SC. (eds.) Handbooks in operations research and management science, pp. 199-226. Elsevier Publisher, Amsterdam (2003).

6. Lee, H.L., Tang, C.S.: Modelling the costs and benefits of delayed product differentiation. Management Science 43(1), 40-53 (1997).

7. Christopher, M.: Logistics and supply chain management: strategies for reducing costs and improving services. 2nd ed. Financial Times, Pitman Publishing, London (1998).

8. Council of Logistics Management.: World class logistics: the challenge of managing continuous change. 1st ed. Council of Logistics Management, Oak Brook, IL (1995).

9. Wang, H-j., Ma, S-h., Zhou, X.: Postponement in mass customization: a literature review. Journal of Donghua University (Eng. ed) 20(4), 111-117 (2003).

10. Yang, B., Burns, N.: Implications of postponement for the supply chain. International Journal of Production Research 41(9), 2075-2090 (2003).

11. Alderson, W.: Marketing efficiency and the principle of postponement. Cost and Profit Outlook 3(4), (1950).

12. Pagh, J.D., Cooper, M.C.: Supply chain postponement and speculation strategies: how to choose the right strategy. Journal of Business Logistics 19(2), 13-33 (1998).

13. Yang, B., Yang, Y.: Postponement in supply chain risk management: a complexity perspective. International Journal of Production Research 48(7), 1901-1912 (2010).

14. Van Hoek, R.I.: The rediscovery of postponement: a literature review and directions for research. Journal of Operations Management 19(2), 161-184 (2001).

15. Van Hoek, R.I.: The thesis of leagility revisited. International Journal of Agile Management Systems 2(3), 196-201 (2000). 
16. Li, J., Cheng, E.T.C., Wang, S.: Analysis of postponement strategy for perishable items by EOQ-based models. International Journal of Production Economics 107(1), 31-38 (2007).

17. Yang, B., Burns, N.D., Backhouse, C.J.: Management of uncertainty through postponement. International Journal of Production Research 42(6), 1049-1064 (2004).

18. Swaminathan, J.M., Tayur, S.R.: Managing broader product lines through delayed differentiation using vanilla boxes. Management Science 44(12-part-2), S161-S172 (1998).

19. García-Dastugue, S.J., Lambert, D.M.: Interorganizational time-based postponement in the supply chain. Journal of Business Logistics 28(1), 57-81 (2007).

20. Cooper, J.C.: Logistics strategies for global businesses. International Journal of Physical Distribution \& Logistics Management 23(4), 12-23 (1993).

21. Mikkola, J.H., Skjøtt-Larsen, T.: Supply-chain integration: implications for mass customization, modularization and postponement strategies. Production Planning \& Control 15(4), 352-361 (2004).

22. Zinn, W., Bowersox, D.J.: Planning physical distribution with the principle of postponement. Journal of Business Logistics 9(2), 117-136 (1988).

23. Yang, B., Burns, N.D., Backhouse, C.J.: The application of postponement in industry. IEEE Transactions on Engineering Management 52(2), 238-248 (2005).

24. Van Hoek, R.I.: Logistics and virtual integration: postponement, outsourcing and the flow of information. International Journal of Physical Distribution \& Logistics Management 28(7), 508-523 (1998).

25. Bowersox, D.J., Closs, D.J.: Logistical management: the integrated supply chain process. International editions ed. McGraw-Hill, Singapore (1996).

26. Waller, M.A., Dabholkar, P.A., Gentry, JJ.: Postponement, product customization, and market-oriented supply chain management. Journal of Business Logistics 21(2), 133-160 (2000).

27. Forza, C., Salvador, F., Trentin, A.: Form postponement effects on operational performance: a typological theory. International Journal of Operations \& Production Management 28(11), 1067-1094 (2008).

28. Cannas, V.G., Pero, M., Rossi, T., Gosling, J.: Integrate customer order decoupling point and mass customisation concepts: a literature review. In: Hankammer, S., Nielsen, K., Piller, F., Schuh, G., Wang, N. (eds.) Customization 4.0. Springer Proceedings in Business and Economics, pp. 495-517. Springer, Cham (2018).

29. Aitken, J., Childerhouse, P., Christopher, M., Towill, D.: Designing and managing multiple pipelines. Journal of Business Logistics 26(2), 73-96 (2005).

30. Garg, A., Tang, C.S.: On postponement strategies for product families with multiple points of differentiation. IIE Transactions 29(8), 641-650 (1997).

31. Tang, C.S.: Perspectives in supply chain risk management. International Journal of Production Economics 103(2), 451-488 (2006).

32. Bucklin, L.P.: Postponement, speculation and the structure of distribution channels. Journal of Marketing Research 2(1), 26-31 (1965).

33. Wikner, J.: An ontology for flow thinking based on decoupling points - unravelling a control logic for lean thinking. Production \& Manufacturing Research 6(1), 433-469 (2018).

34. Wikner, J.: On decoupling points and decoupling zones. Production \& Manufacturing Research 2(1), 167-215 (2014).

35. Andries, B., Gelders, L.: Time-based manufacturing logistics. Logistics Information Management 8(3), 30-36 (1995).

36. Lee, H.L.: Postponement for mass customization: satisfying customer demands for tailormade products. In: Gattorna, J. (ed.) Strategic supply chain alignment: best practice in supply chain management, pp. 77-91. Gower, Aldershot (1998). 